\title{
Isolation of indigenous strains of entomopathogenic fungi from rice ecosystems using mycosed cadavers and galleria bait method
}

\section{MALINI NILAMUDEEN AND K. SUDHARMA}

Article Chronicle :

Received :

26.04.2017;

Accepted :

28.11.2017
Author for correspondence :

MALINI NILAMUDEEN Institute for Watershed

Development and

Management,

Chadayamangalam, KOLLAM (KERALA) INDIA

See end of the article for

Coopted authors'

HOW TO CITE THIS ARTICLE : Nilamudeen, Malini and Sudharma, K. (2017). Isolation of indigenous strains of entomopathogenic fungi from rice ecosystems using mycosed cadavers and galleria bait method. Asian J. Environ. Sci., 12(2): 135-137, DOI: 10.15740/HAS/AJES/12.2/135-137.

Key Words : Indigenous strains, Entomopathogenic fungi, Rice ecosystems, Using mycosed, Cadavers, Galleria bait method

$\mathrm{G}$ lobally, many technologies have been developed for managing the most noxious pests - the insects that limit agricultural production, of which, many have been forsaken. Today, research converges to biological control by virtue of the effectiveness of the bio agents and their safety to nontargets and environment. The naturally existing and disease causing microbes of insects are applauded as important biocontrolagents world over and research is spinning ahead for exploiting their potential. Soil and insect cadavers present in natural ecosystems are rich sources of entomopathogenic fungi (Ignoffo et al., 1978). The present report focused on the isolation and identification of indigenous strains of entomopathogenic fungi from rice ecosystem.

Periodic surveys were conducted at monthly intervals in thirty rice fields for a period of one year for collecting entomopathogenic fungi from rice ecosystem. Two different methods were followed for the collection of mycosed insects. In the first method, dead insects were collected directly from the rice ecosystem. Insect cadavers collected were brought to laboratory for isolation of fungi, if any. In the second method, sweep net collection of insects were taken and live insects were brought to laboratory, reared and observed regularly for the development of symptoms of fungal infection, if any.

The cadavers collected were kept separately in nine $\mathrm{cm}$ Petri plates with moistened filter papers for development of fungal growth. Those cadavers with fungal growth were then surface sterilized for one min in 0.1 per cent mercuric chloride and this was followed by three repeated washings in sterile water under aseptic conditions in a laminar air flow chamber (Hareedranath, 1989). After wards, the specimens were dried by keeping it in sterilized filter paper for two min. The cadavers were then placed in Petri plates with potato dextrose Agar (PDA) for development of mycelia. After the mycelial development, sub culturing was done for thrice, transferred to PDA slants and purified by hyphal tip method (Cloh, 1999). The fungi thus obtained were maintained in PDA slants 